\title{
Radiologic hand and wrist changes in systemic sclerosis: associations with disease duration, skin score, and capillaroscopy
}

\author{
Sepideh Sefidbakht ${ }^{1}$, Saeedeh Shenavandeh ${ }^{2 *}$, Kamran Rasekh ${ }^{3}$, MohammadAli Nazarinia ${ }^{2,4}$ \\ ${ }^{1}$ Departments of Radiology, Shiraz University of Medical Sciences, Shiraz ,Iran. ${ }^{2}$ Department of Internal Medicine, \\ Division of Rheumatology, Shiraz University of Medical Sciences, Shiraz, Iran. ${ }^{3}$ Departments of Internal Medicine, \\ Shiraz University of Medical Sciences, Shiraz, Iran. ${ }^{4}$ Shiraz geriatric research center, Shiraz university of medical \\ sciences, Shiraz, Iran.
}

\begin{abstract}
Patients with systemic sclerosis (SSc) have some musculoskeletal manifestations. The radiologic manifestations can be articular or non-articular. There is inconsistency in the correlation between clinical manifestations and radiologic changes; there are few reports on the correlation between them and capillaroscopy.

A total of 81 patients with SSc who referred to a scleroderma clinic affiliated with Shiraz University of Medical Sciences, Iran, were evaluated in this cross-sectional, single-center study. Skin score test and capillaroscopy were performed, and an expert radiologist evaluated the posterior-anterior views of both hands and wrists. Data was analyzed using SPSS version 19.

The participants consisted of 73 women and eight men aged $42 \pm 2.6$ years old, $60.5 \%$ of whom had limited scleroderma (lcSSc) and $39.5 \%$ had diffuse scleroderma (dcSSc). After 5 years, $91 \%$ of them had some radiologic changes, most of which were asymptomatic.

The most common radiologic changes were non-articular (70.1\%), including acro-osteolysis, subcutaneous and peri-articular calcinosis, and avascular necrosis. Flexion deformities and DIP joint space narrowing were seen more in patients with dcSSc. Resorption of the distal ulna and avascular necrosis was observed more in lcSSc. There was a correlation between radiologic changes and duration, but not with skin score. The most common capillaroscopic pattern in patients with radiologic change was late scleroderma pattern.

Radiologic changes, which were mostly asymptomatic, were common in patients with SSc. The changes were different in patients with dcSSc and lcSSc and there were associations with duration and capillaroscopic patterns, but not with skin score.
\end{abstract}

Keywords: Systemic sclerosis, skin, radiology, nailfold capillaroscopy

\section{Introduction}

Systemic sclerosis $(\mathrm{SSc})$ is a rare connective tissue disease seen in less than one of every 2000 people and affects mostly the skin and internal organs [1]. It also has some common musculoskeletal manifestations including myalgia, muscle atrophy, arthralgia, arthritis, tendon sheath involvement, impaired finger-palm distance, and/or flexion contractures predominantly in the fingers, wrists, and ankles [2,3].

Osteolysis, or bony resorption, has been reported not only in the terminal digital tufts of the fingers and toes, but also in the distal clavicle, ribs, cervical spine, and mandibular angles [2]. In one study, two thirds of patients with SSc had abnormalities in their hand X-rays, mostly acro-osteolysis, calcinosis, flexion contracture, erosions, and joint space narrowing, some of them being related to disease duration and certain clinical findings [4]. Radiologic abnormalities of the joints can also be divided into inflammatory (including juxta-articular osteoporosis, joint space narrowing, and erosions) and degenerative and peri-articular fibrotic (including digital flexion) patterns [5]. Articular involvement of patients with SSc could be due to periarticular fibrosis, synovitis, or when there is an overlap, with rheumatoid arthritis $[6,7]$. There are case reports of osteonecrosis as an under-recognized cause of wrist pain in patients with SSc and no history of receiving high doses of corticosteroids, probably secondary to both macro- and micro-vascular abnormalities that are parts of the underlying disease process $[2,8,9]$. Several studies have evaluated the correlation of radiologic hand manifestations with clinical and serological findings. One research study found that there was no relationship with either of them [5]; another study showed that organ involvement and SSc-associated autoantibodies had a relationship with hand radiographic abnormalities [4].

Personal non-commercial use only.Rheumatology Research Journal. Copyright (C) 2019. All rights reserved

*Corresponding Author: Saeedeh Shenavandeh, MD, Shiraz University of Medical Sciences, Departments of Internal Medicine, Division of Rheumatology, Shiraz ,Iran, Email: shenavande@sums.ac.ir, Tel/Fax: (+98) 713-6474316 Po Box: $71345-1414$

Received: 18 January 2020; Accepted: 26 May 2020 
Nailfold capillaroscopy is a major investigation tool for rheumatologists evaluating the microcirculatory involvement of patients with scleroderma and is part of the EULAR/ACR criteria for SSc. There are multiple previous and ongoing studies regarding its prognostic value and correlation between severity of SSc and current staging systems of nailfold capillaroscopy [10]. Only one previous study has evaluated the association of calcinosis and acro-osteolysis with specific NVC features and showed the association of late scleroderma capillaroscopic pattern, especially severe capillary loss, with acro-osteolysis and calcinosis [11].

In the present study, all radiologic changes of the hand and wrist in patients with SSc, which were divided into limited (lcSSc) and diffuse systemic sclerosis (dcSSc), were evaluated, and the association between changes and skin score, disease duration (five years before and after onset of sclerosis of skin), and capillaroscopic manifestations in patients was determined.

\section{Materials and Methods}

This single-center cross-sectional study was conducted with SSc patients referring to the Hafez Hospital Clinic of Scleroderma, affiliated with Shiraz University of Medical Science, from April 2012 to April 2014.

All patients who fulfilled the ACR criteria [12] and (2013) ACR/EULAR SSc diagnostic criteria [13] for SSc and were eligible for capillaroscopy and radiologic hand and wrist X-ray met the inclusion criteria. Cases with overlap syndrome, smokers, diabetes mellitus, pregnant, and those with the past history of trauma to the hands and wrist were excluded from the study.

All demographic and clinical manifestations of the patients and their organ involvement including their Modified Rodnan Skin Score (MRSS( [14] were recorded during evaluation. Patients were divided into dcSSc and
lcSSc subsets according to LeRoy et al. [15]. On the same day, capillaroscopy (using digital streomicroscopy by the power of $\times 250$, Euromex ST. 1740, made in Holland, and video camera Cmex D.C.5000 with 5 megapixels) was performed by the rheumatologist involved in the research who evaluated eight fingers of the two hands excluding the thumbs. Findings were recorded as normal, scleroderma patterns of early, active, or late, or non-specific abnormalities based on Cutulo et al. [16]. On the same day, radiologic evaluation of the posterior-anterior views of both hands and wrists was requested. An expert radiologist blinded to the clinical manifestations of patients evaluated the X-ray manifestations, which were divided into articular and non-articular types. The skin score changes were classified into 3 groups: mild $(<15)$, moderate $(\geq 15$ to $<30)$, or severe $(\geq 30)$ [18].

Informed consent was obtained from all participants, and the study was approved by the Ethics Committee of Shiraz University of Medical Sciences.

Assessment and analysis were done using SPSS, version 19. All data is presented as means and SDs for continuous variables and numbers and percentages for categorical variables. For differences in frequency, the chi-square and Fisher Exact tests were used. A value of $p<0.05$ was considered statistically significant.

\section{Results}

A total of $81 \mathrm{SSc}$ patients fulfilled the inclusion criteria during the study period ( 73 women and 8 men). The participants' ages ranged from 22 to 80 years (mean: $42 \pm 2.6)$. There were $49(60.49 \%)$ cases of $1 \mathrm{cSSc}$ and $32(39.51 \%)$ cases of dcSSc. The patients' characteristics based on disease duration, skin score, and capillaroscopic manifestations are shown in Table 1.

Table 1. Classification of SSc patients based on duration, pattern of capillaroscopy and skin score in dcSSc and lcSSc patients

\begin{tabular}{|c|c|c|c|c|c|c|c|c|}
\hline & \multicolumn{2}{|c|}{ Duration } & \multirow{2}{*}{$\begin{array}{c}\text { Non-specific } \\
\text { capillary abnor- } \\
\text { malities (N:9) } \\
\\
-\end{array}$} & \multicolumn{3}{|c|}{$\begin{array}{l}\text { the Scleroderma pattern of } \\
\text { Capillaroscopy } \\
\text { (N:72)the Scleroderma pattern of } \\
\text { Capillaroscopy } \\
\text { (N:72)the Scleroderma pattern of } \\
\text { Capillaroscopy } \\
\text { (N:72) }\end{array}$} & \multicolumn{2}{|c|}{ Skin score (N:81) } \\
\hline & $\begin{array}{c}<5 \text { years } \\
\mathrm{N}(\%)\end{array}$ & $\begin{array}{c}\geq 5 \text { years } \\
\mathrm{N}(\%)\end{array}$ & & $\begin{array}{l}\text { Early } \\
\mathrm{N}(\%)\end{array}$ & $\begin{array}{l}\text { Active } \\
\mathrm{N}(\%)\end{array}$ & $\begin{array}{l}\text { Late } \\
\mathrm{N}(\%)\end{array}$ & $\begin{array}{l}\text { Mild } \\
\mathrm{N}(\%)\end{array}$ & $\begin{array}{c}\text { Moderate to severe } \\
\mathrm{N}(\%)\end{array}$ \\
\hline $\begin{array}{l}\text { Total } \\
\text { N: } 81\end{array}$ & $10(12.4)$ & $71(87.6)$ & $9(11.4)$ & $8(9)$ & $28(34.7)$ & $36(44.9)$ & $42(51.8)$ & $39(48.2)$ \\
\hline $\begin{array}{l}\mathrm{dcSSc} \\
\mathrm{N}: 32\end{array}$ & $3(9.4)$ & $29(90.6)$ & $0(0)$ & $1(3.15)$ & $13(40.6)$ & $18(56.25)$ & $6(18.75)$ & $26(81.25)$ \\
\hline $\begin{array}{l}1 \mathrm{lcSSc} \\
\mathrm{N}: 49\end{array}$ & $7(14.3)$ & $42(85.7)$ & $9(18.3)$ & $7(14.3)$ & $15(30.7)$ & $18(36.7)$ & $36(73.4)$ & $13(26.6)$ \\
\hline
\end{tabular}

SSc: systemic sclerosis, dcSSc: diffuse systemic sclerosis, lcSSc: limited systemic sclerosis 
In evaluations of the hand radiologic manifestations, 67 patients $(82.7 \%)$ had radiologic changes, while 14 patients $(17.2 \%)$ did not. Among patients with a disease duration of $>5$ years, $91 \%$ had radiologic changes.

The most common radiologic changes were non-articular, 70.1\% accounted for by absorption of the distal phalanges (acro-osteolysis), flexion deformities, soft tissue calcinosis, para-articular calcifications, and avascular necrosis, respectively. The most common articular changes were distal interphalangeal (DIP) and proximal interphalangeal (PIP) joint space narrowing (29.9\% and $26.8 \%$, respectively). All radiologic changes and differences between dcSSc and lcSSc are shown in Table 2 and Figure 1.

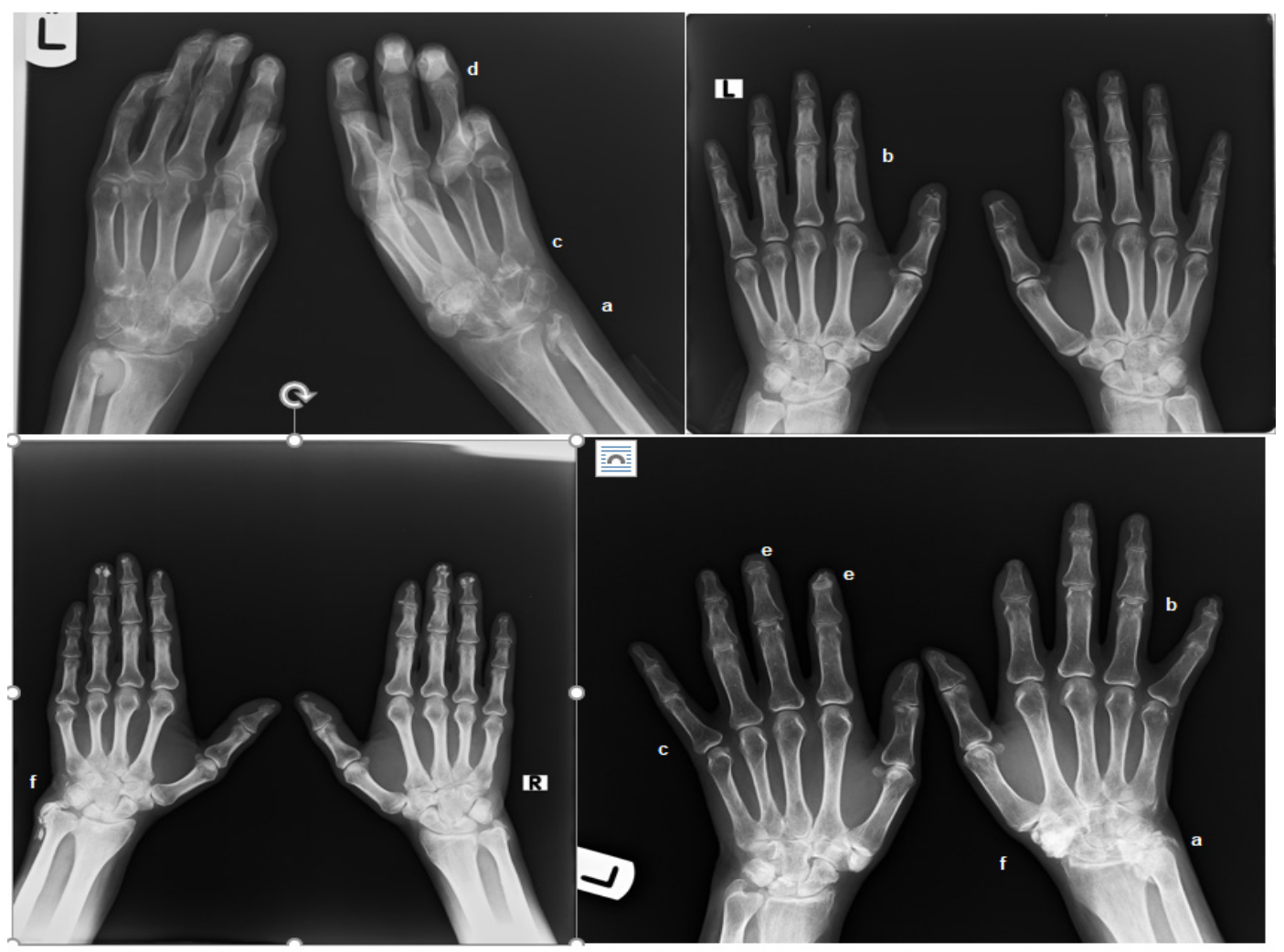

Figure1. Radiologic changes in patients with SSc, a) resorption of distal ulna, b) joint space narrowing in PIP, DIP and carpal joints, c) juxta-articular osteoporosis, d) flexion deformities, e) absorption of distal phalanges (acro-osteolysis), and f) soft tissue calcinosis

Table 2. Articular and extra-articular radiologic changes in SSc patients

\begin{tabular}{cccccc}
\hline & & $\begin{array}{c}\text { Total with } \\
\text { radiologic } \\
\text { change }\end{array}$ & $\begin{array}{c}\text { With radiologic } \\
\text { change }\end{array}$ & $\begin{array}{c}\text { With radiologic } \\
\text { change }\end{array}$ & $\begin{array}{c}\text { P.value* } \\
\text { (comparing patients } \\
\text { with limited and } \\
\text { diffuse SSc) }\end{array}$ \\
\hline Non-articular changes & & & & & \\
\hline Flexion deformities & Yes & $25(37.3 \%)$ & $15(55.5 \%)$ & $10(25 \%)$ & 0.015 \\
& No & $42(62.7 \%)$ & $12(46.5 \%)$ & $30(75 \%)$ & 0.441 \\
Soft tissue calcinosis & Yes & $21(31.3 \%)$ & $10(37 \%)$ & $11(27.5 \%)$ & $29(72.5 \%)$ \\
Para-articular & No & $46(68.7 \%)$ & $17(63 \%)$ & $8(20 \%)$ & $32(80 \%)$ \\
calcifications & Yes & $14(20.8 \%)$ & $6(22.2 \%)$ & $21(77.8 \%)$ & 0.778 \\
\hline
\end{tabular}




\begin{tabular}{|c|c|c|c|c|c|}
\hline & & $\begin{array}{l}\text { Total with } \\
\text { radiologic } \\
\text { change }\end{array}$ & $\begin{array}{c}\text { deSSc } \\
\text { With radiologic } \\
\text { change }\end{array}$ & $\begin{array}{c}\text { IcSSc } \\
\text { With radiologic } \\
\text { change }\end{array}$ & $\begin{array}{c}P \text { value* } \\
\text { (comparing patients } \\
\text { with limited and } \\
\text { diffuse SSc) }\end{array}$ \\
\hline \multirow{2}{*}{$\begin{array}{c}\text { Absorption of distal } \\
\text { phalanges (acro-osteolysis) }\end{array}$} & Yes & $47(70.1 \%)$ & $20(74 \%)$ & $27(67.5 \%)$ & \multirow{2}{*}{0.646} \\
\hline & No & $20(29.9 \%)$ & $7(26 \%)$ & $13(32.5 \%)$ & \\
\hline Resorption of distal & Yes & $13(19.7 \%)$ & $2(7.4 \%)$ & $11(27.5 \%)$ & \multirow{2}{*}{0.066} \\
\hline ulna & No & $54(81.3 \%)$ & $25(92.6 \%)$ & $29(72.5 \%)$ & \\
\hline \multirow{2}{*}{ Avascular necrosis } & Yes & $8(11.9 \%)$ & $2(7.4 \%)$ & $6(15 \%)$ & \multirow{2}{*}{0.118} \\
\hline & No & $59(88.1 \%)$ & $25(92.6 \%)$ & $34(85 \%)$ & \\
\hline \multicolumn{6}{|l|}{ Articular change } \\
\hline Juxta-articular & Yes & $9(13.4 \%)$ & $4(14.8 \%)$ & $5(12.5 \%)$ & \multirow{2}{*}{0.748} \\
\hline osteoporosis & No & $58(86.6 \%)$ & $23(85.2 \%)$ & $35(87.5 \%)$ & \\
\hline \multirow{2}{*}{ Joint space narrowing: } & Yes & $21(31.3 \%)$ & $12(44.4 \%)$ & $9(22.5 \%)$ & \multirow{2}{*}{0.033} \\
\hline & No & $46(68.7 \%)$ & $15(55.6 \%)$ & $31(87.5 \%)$ & \\
\hline \multirow{2}{*}{ Distal interphalangeal joints (DIP) } & Yes & $16(29.9 \%)$ & $11(40.7 \%)$ & $5(12.5 \%)$ & \multirow{2}{*}{0.036} \\
\hline & No & $51(70.1 \%)$ & $16(59.3 \%)$ & $35(87.5 \%)$ & \\
\hline \multirow{2}{*}{$\begin{array}{c}\text { Proximal interphalangeal joints } \\
\text { (PIP) }\end{array}$} & Yes & $18(26.8 \%)$ & $10(37 \%)$ & $8(20 \%)$ & \multirow{2}{*}{0.163} \\
\hline & No & $49(73.2 \%)$ & $17(63 \%)$ & $32(80 \%)$ & \\
\hline \multirow{2}{*}{ Carpal joints } & Yes & $6(8.9 \%)$ & $2(7.4 \%)$ & $4(10 \%)$ & \multirow{2}{*}{0.112} \\
\hline & No & $61(91.1 \%)$ & $25(92.6 \%)$ & $36(90 \%)$ & \\
\hline \multirow{2}{*}{ Erosions: } & Yes & $12(17.9 \%)$ & $5(18.5 \%)$ & $7(17.5 \%)$ & \multirow{2}{*}{0.498} \\
\hline & No & $55(82.1 \%)$ & $22(81.5 \%)$ & $33(82.5 \%)$ & \\
\hline \multirow{2}{*}{ Wrists } & Yes & $6(8.9 \%)$ & $2(7.4 \%)$ & $4(10 \%)$ & \multirow{2}{*}{0.819} \\
\hline & No & $61(81.9 \%)$ & $25(92.6 \%)$ & $36(90 \%)$ & \\
\hline \multirow{2}{*}{ MCP joints } & Yes & $10(14.9 \%)$ & $4(14.8 \%)$ & $6(15 \%)$ & \multirow{2}{*}{0.605} \\
\hline & No & $57(85.1 \%)$ & $23(85.2 \%)$ & $34(85 \%)$ & \\
\hline \multirow{2}{*}{ PIP joints } & Yes & $6(8.9 \%)$ & $2(7.4 \%)$ & $4(10 \%)$ & \multirow{2}{*}{0.551} \\
\hline & No & $61(91.1 \%)$ & $25(92.6 \%)$ & $36(90 \%)$ & \\
\hline \multirow{2}{*}{ DIP joints } & Yes & $5(7.4 \%)$ & $3(11.1 \%)$ & $2(5 \%)$ & \multirow{2}{*}{0.054} \\
\hline & No & $62(92.6 \%)$ & $24(88.9 \%)$ & $38(95 \%)$ & \\
\hline \multirow{2}{*}{$\begin{array}{c}\text { Subluxation/dislocation of pha- } \\
\text { langes }\end{array}$} & Yes & $7(10.4 \%)$ & $4(14.8 \%)$ & $3(7.5 \%)$ & \multirow{2}{*}{0.426} \\
\hline & No & $60(89.6 \%)$ & $23(85.2 \%)$ & $37(92.5 \%)$ & \\
\hline \multirow{2}{*}{ Subchondral sclerosis } & Yes & $1(1.4 \%)$ & $0(0 \%)$ & $1(2.5 \%)$ & \multirow{2}{*}{0.416} \\
\hline & No & $66(98.6 \%)$ & $27(100 \%)$ & $39(97.5 \%)$ & \\
\hline S 1 & Yes & $4(5.9 \%)$ & $1(3.7 \%)$ & $3(7.5 \%)$ & $0<0$ \\
\hline & No & $63(94.1 \%)$ & $26(96.3 \%)$ & $37(92.5 \%)$ & \\
\hline
\end{tabular}

* $P$ value less than 0.05 was considered significant 
In evaluations of the correlation between hand symptoms and radiologic findings, based on the history and clinical hand and wrist examination, none of the SSc patients who had no radiologic change had a history of arthralgia or pain in examination of their wrists. In patients with radiologic changes, only $34 \%$ had a history of arthralgia or pain on motion in the joint exam; $19 \%$ of them were dcSSc and $15 \%$ were $1 \mathrm{cSSc}$ cases.

A significant correlation was found between radiologic changes and disease duration in all SSc patients (p-value $=$ 0.042). In patients with dcSSc and lcSSc, radiologic changes were correlated with duration of the diseases as well (Table 3 ).

Table 3. Comparison of radiologic changes of the hands and wrists with duration in dcSSc and lcSSc patients with more or less than 5 years of the duration of the disease

\begin{tabular}{ccccc}
\hline $\begin{array}{c}\text { Patients with radiologic } \\
\text { change }\end{array}$ & Total 67(100\%) & $\begin{array}{c}\text { Duration<5 years } \\
\mathbf{6 ( 8 . 9 \% )}\end{array}$ & $\begin{array}{c}\text { Duration } \geq \mathbf{5} \\
\mathbf{6 1}(\mathbf{9 1 \%} \%\end{array}$ & $\boldsymbol{P . v a l u e *}$ \\
\hline $\mathrm{dcSSc}$ & $26(100 \%)$ & $2(7.6 \%)$ & $24(92.4 \%)$ & 0.042 \\
$\mathrm{lcSSc}$ & $41(100) \%$ & $4(9.7 \%)$ & $37(90.3 \%)$ & \\
\hline
\end{tabular}

*P value less than 0.05 was considered significant
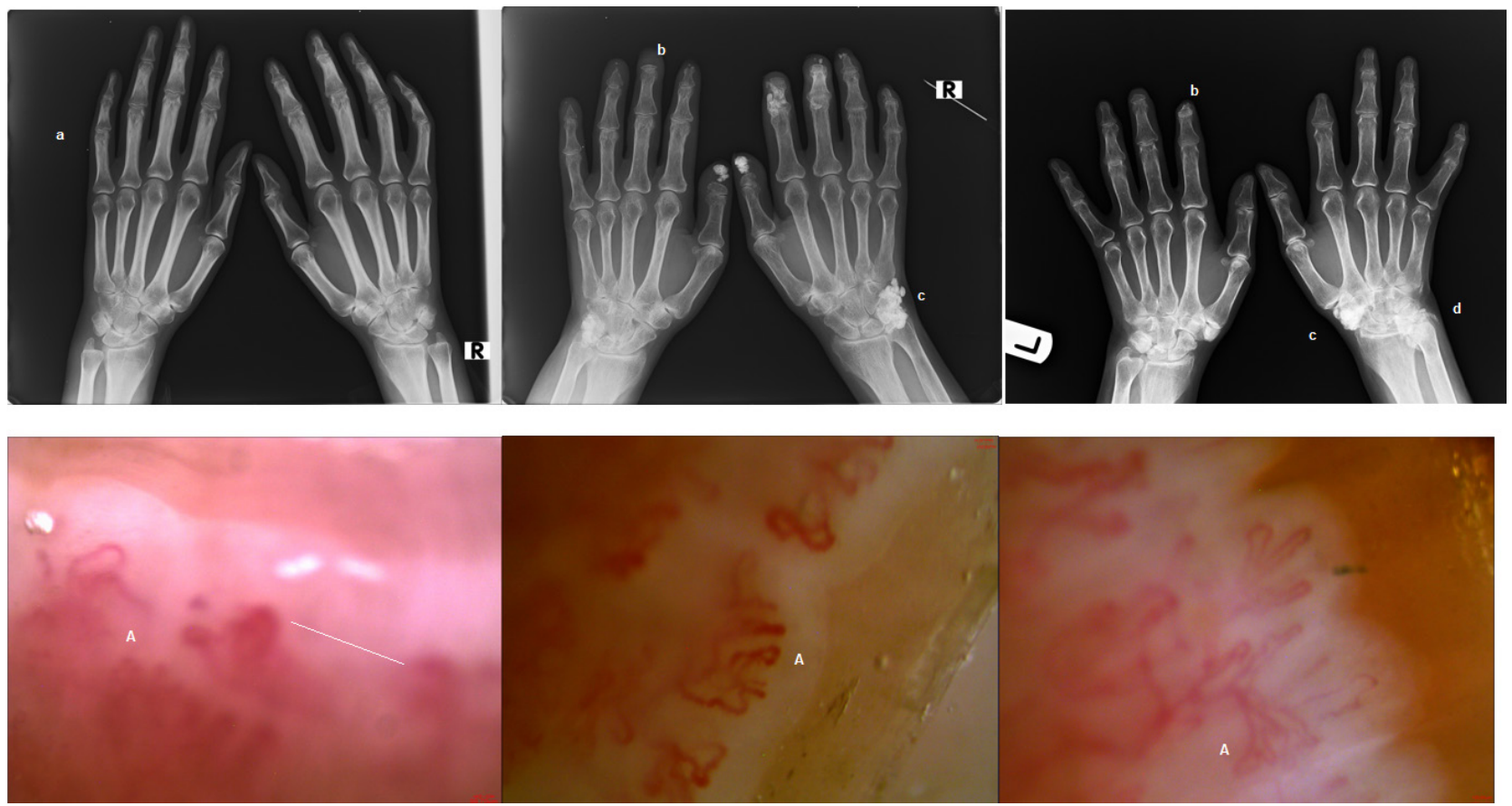

Figure2. Capillaroscopic changes correlated to radiologic changes in patients with SSc, a) joint space narrowing in PIP and DIP joints, b) absorption of distal phalanges, c) soft tissue calcinosis, a-resorption of distal ulna, A-Multiple increased ramification and neoangiogenesis in capillaroscopy in favour of late scleroderma pattern, Line-capillary loss and decreased number in capillaroscopy

There were $42(51.8 \%)$ patients with a mild skin score, 34 (50.7\%) of whom had radiologic changes; $39(48.2 \%)$ patients had a moderate to severe skin score, 33(49.3\%) of whom had radiologic changes. There was no relationship between the skin score and radiologic changes. No skin score $>40$ was seen in this study, so the very severe skin score was not used.

Capillaroscopy showed there were 9 patients with non-spe- cific capillary abnormalities and 72 patients with scleroderma capillaroscopic pattern. The most common capillaroscopic pattern in all patients was late scleroderma pattern and the least frequent pattern was early scleroderma pattern (Tables 1 and 4) (Figure 2). 
Table 4. Different scleroderma patterns of capillaroscopy in patients with dcSSc and lcSSc along with radiologic changes

\begin{tabular}{|c|c|c|c|c|}
\hline \multirow{2}{*}{ Number and type } & $\begin{array}{l}\text { pattern of } \\
\text { scopy }\end{array}$ & $\begin{array}{l}\text { Early scleroder- } \\
\text { ma pattern }\end{array}$ & $\begin{array}{l}\text { Active scleroder- } \\
\text { ma pattern }\end{array}$ & Late scleroderma pattern \\
\hline & & & & \\
\hline Total :72 & $\begin{array}{l}\text { With radiologic change } \\
58(100 \%)\end{array}$ & $5(8.6 \%)$ & $20(34.5 \%)$ & $33(56.9 \%)$ \\
\hline Diffuse:29 & $\begin{array}{l}\text { With radiologic change } \\
26(100 \%)\end{array}$ & $1(3.9 \%)$ & $9(34.6 \%)$ & $16(61.5 \%)$ \\
\hline Limited:43 & $\begin{array}{l}\text { With radiologic change } \\
32(100 \%)\end{array}$ & $4(12.5 \%)$ & $11(34.4 \%)$ & $17(53.1 \%)$ \\
\hline
\end{tabular}

In those with early scleroderma capillaroscopic pattern $[n=8]$, patients with radiologic changes [5 (62.5\%)] were compared to those without radiologic changes, and the p-value was not significant ( $P$ value: 0.48 ). In patients with active scleroderma capillaroscopic pattern $[\mathrm{n}=28]$, those with radiologic changes [20 (71.4\%)] were compared to patients without radiologic changes, and the p-value was not significant (p-value: 0.203 ). In patients with late scleroderma capillaroscopic pattern $[\mathrm{n}=36]$, there were significantly more patients with radiologic changes [33 $(91.6 \%)]$ than patients without radiologic changes, and the p-value was significant ( $P$ value: $0.000)$. This correlation was seen in both dsSSc and lcSSc patients. This correlation was also seen in dsSSc patients with late pattern [18 (56.25\%)]; among them, $16(61.5 \%)$ had radiologic changes ( $P$ value: 0.005$)$. It was further seen in $1 \mathrm{SSSc}$ patients with late pattern [18 (36.7\%)], of whom $17(53.1 \%)$ had radiologic changes ( $P$ value: 0.000$)$.

\section{Discussion}

Radiologic manifestations of the hands and wrists were evaluated in patients with scleroderma; the results showed that radiologic hand and wrist changes, especially non-articular involvements, were common in patients with SSc. In the current study, $82.7 \%$ of all patients had radiologic changes; after 5 years, the changes were seen in $91 \%$ of patients, and most of them were asymptomatic. The most common radiologic changes were non-articular $(70.1 \%)$, especially acro-osteolysis. It was also found that the duration and the late scleroderma capillaroscopic pattern was associated more with radiologic changes.

The high prevalence of radiologic changes in patients with $\mathrm{SSc}$ in this study was similar to a study carried out by $\mathrm{La}$ Montagna et al. that showed almost all patients ( 75 from 76 patients) had at least one feature of fibrotic, inflammatory, or degenerative changes in radiologic evaluations of the hands and/or feet [5].
The current study also found that with increasing duration of SSc, the articular and non-articular changes became more common, although they were asymptomatic in some patients. Patient history and physical exam showed a lower number of patients with joint involvement, but radiology showed the involvement of the hands and wrists in most patients with scleroderma; the same result was reported by studies which used ultrasound (US) for detecting early musculoskeletal changes in patients with scleroderma [6].

In the current study, the most common radiologic changes were non-articular, including absorption of distal phalanges (acro-osteolysis) and then flexion deformities, soft tissue calcinosis, para-articular calcifications, and avascular necrosis. In the study performed by La Montagna, diffuse osteopenia and flexion deformities were the most common, and absorption of distal phalanges was the third most common hand articular radiologic changes in all patients. In the present study, DIP and PIP joint space narrowing, MCP joint erosions, and juxta-articular osteoporosis were observed to be the most common articular presentations, in line with the study carried out by La Montagna [5]. Subcutaneous calcinosis has been reported in $20 \%-40 \%$ of patients with SSc [17], which is similar to the SSc patients in the current study, $31.3 \%$ of whom had soft tissue calcinosis and $20.8 \%$ had para-articular calcifications.

In dcSSc and lcSSc patients, the most common articular changes were joint space narrowing; flexion deformities and DIP joint space narrowing were more commonly observed in dcSSc patients than in those with lcSSc. Resorption of the distal ulna and avascular necrosis was more common in patients with lcSSc, although due to the low number of patients it was not significant.

In the current study, avascular necrosis (AVN) in the lunate bone was observed in 8 patients with SSc, mostly in the lcSSc group. AVN has been seen in few case reports so far, and it 
seems that this can happen only rarely, especially in patients with limited scleroderma; it should be considered as a cause of their wrist complaints. A previous study described three cases of osteonecrosis of the lunate bone of the wrist in patients with SSc presenting with wrist pain. All of them had lcSSc. Another report was a case of scleroderma with severe Raynaud's phenomenon, in whom bilateral aseptic necrosis of the lunate bones developed. In Eular's 2017 study, 3 cases of lunate avascular necrosis were reported [2, 8, 9, 18].

The current study showed that in all patients with radiologic changes, there was no correlation with skin score; therefore, in each skin score, radiologic joint involvement should be a concern. La Montagna et al. showed that articular involvement had no correlation to clinical or serological manifestations of patients with SSc; there was only a correlation between flexion contractures in the hands and a radiological fibrotic pattern and that of skin score [5]. In another study using ultrasonography, the researchers found a significant correlation between the presence of tenosynovitis and a higher modified Rodnan skin thickness score [8].

In the present study, each scleroderma capillaroscopic pattern was compared with radiologic changes, revealing that most of the patients with radiologic changes had late scleroderma capillaroscopic pattern, and early pattern was least observed. Late scleroderma capillaroscopic pattern was associated more with radiologic changes than with early and active patterns. Freire et al. evaluated the ultrasonography changes of the wrists and hands in patients with SSc and found no difference between patients who had capillaroscopic patterns with and without US involvement of the hands and wrists [19]. Like the current study results, Morardet et al. evaluated the correlation of calcinosis and acro-osteolysis as a disabling hand manifestation to nailfold capillaroscopy pattern and found an association of the radiologic hand features with the late scleroderma pattern and particularly with severe capillary loss [11].

The current study was limited by the low number of early $(<5$ years duration) scleroderma patients. Moreover, despite the inclusion of $81 \mathrm{SSc}$ patients, the number of patients with every single radiologic manifestations like calcinosis or avascular necrosis was limited. Therefore, making definite statements based on these results may be difficult. Further evaluations comparing ultrasound and radiologic sensitivities in detecting early scleroderma musculoskeletal manifestations and correlations of each radiologic change with capillaroscopy are recommended for future studies.

\section{Conclusion}

Radiologic (especially non-articular) changes are very common in patients with SSc, and most of them are asymptomatic. The changes are different in patients with diffuse and limited sclerosis, and there are associations with duration and capillaroscopic patterns, but there is no association with the skin score. In patients with limited scleroderma, avascular necrosis of the lunate bone should always be taken into account.

\section{Acknowledgments}

The present article was extracted from the thesis written by Dr. Kamran Rasekhi, supported by Shiraz University of Medical Sciences grant number: 91-01-01-5568. The authors would like to thank Shiraz University of Medical Sciences, Shiraz, Iran, the Center for Development of Clinical Research of Namazi Hospital, and Dr. Nasrin Shokrpour for her editorial assistance.

\section{Conflict of Interest}

The authors declare no conflicts of interest. 


\section{References}

1. Carrier M-E, Kwakkenbos L, Nielson WR, Fedoruk C, Nielsen K, Milette K, et al. The Scleroderma Patient-Centered Intervention Network Self-Management Program: Protocol for a Randomized Feasibility Trial. JMIR Res Protoc 2020; 9(4):e16799. doi: 10.2196/16799.

2. Shah AA, Wigley FM. Often forgotten manifestations of systemic sclerosis. Rheum Dis Clin North Am 2008; 34(1):221-38; ix. doi: 10.1016/j.rdc.2007.10.002.

3. Ingegnoli F, Galbiati V, Zeni S, Meani L, Zahalkova L, Lubatti C, et al. Use of antibodies recognizing cyclic citrullinated peptide in the differential diagnosis of joint involvement in systemic sclerosis. Clin Rheumatol 2007; 26(4):510-14. doi: 10.1007/s10067-006-0313-3.

4. Sakata K, Kaneko Y, Yasuoka H, Takeuchi T. Association of radiographic findings in hand X-ray with clinical features and autoantibodies in patients with systemic sclerosis. Clin Rheumatol 2020; 39(1):113-18. doi: 10.1007/ s10067-019-04639-6.

5. La Montagna G, Sodano A, Capurro V, Malesci D, Valentini G. The arthropathy of systemic sclerosis: a 12 month prospective clinical and imaging study. Skeletal Radiol 2005; 34(1):35-41. doi: 10.1007/s00256-004-0830-6.

6. Cuomo G, Zappia M, Abignano G, Iudici M, Rotondo A, Valentini G. Ultrasonographic features of the hand and wrist in systemic sclerosis. Rheumatology (Oxford) 2009; 48(11):1414-17. doi: 10.1093/rheumatology/kep250.

7. Elhai M, Guerini H, Bazeli R, Avouac J, Freire V, Drape $\mathrm{JL}$, et al. Ultrasonographic hand features in systemic sclerosis and correlates with clinical, biologic, and radiographic findings. Arthritis Care Res (Hoboken) 2012; 64(8):1244-49. doi: 10.1002/acr.21668.

8. Agus B. Bilateral aseptic necrosis of the lunate in systemic sclerosis. Clin Exp Rheumatol 1987; 5(2):155-57.

9. Matsumoto AK, Moore R, Alli P, Wigley FM. Three cases of osteonecrosis of the lunate bone of the wrist in scleroderma. Clin Exp Rheumatol 1999; 17(6):730-32.

10. Boulon C, Aiouaz S, Blaise S, Mangin M, Decamps-Le Chevoir J, Senet P, et al. Correlation between capillaroscopic classifications and severity in systemic sclerosis: results from the SCLEROCAP study at inclusion. Clin Exp Rheumatol 2019; 37(4):63-68.
11. Morardet L, Avouac J, Sammour M, Baron M, Kahan A, Feydy A, et al. Late Nailfold Videocapillaroscopy Pattern Associated With Hand Calcinosis and Acro-Osteolysis in Systemic Sclerosis. Arthritis Care Res (Hoboken) 2016; 68(3):366-73. doi: 10.1002/acr.22672.

12. Preliminary criteria for the classification of systemic sclerosis (scleroderma). Subcommittee for scleroderma criteria of the American Rheumatism Association Diagnostic and Therapeutic Criteria Committee. Arthritis Rheum 1980; 23(5):581-90. doi: 10.1002/art.1780230510.

13. van den Hoogen F, Khanna D, Fransen J, Johnson SR, Baron M, Tyndall A, et al. 2013 classification criteria for systemic sclerosis: an American College of Rheumatology/European League against Rheumatism collaborative initiative. Arthritis Rheum 2013; 65(11):2737-47. doi: 10.1002/art.38098.

14. Clements PJ, Lachenbruch PA, Ng SC, Simmons M, Sterz M, Furst DE. Skin score. A semiquantitative measure of cutaneous involvement that improves prediction of prognosis in systemic sclerosis. Arthritis Rheum 1990; 33(8):1256-63. doi: 10.1002/art.1780330828.

15. LeRoy EC, Black C, Fleischmajer R, Jablonska S, Krieg T, Medsger TA, Jr., et al. Scleroderma (systemic sclerosis): classification, subsets and pathogenesis. J Rheumatol 1988; 15(2):202-05.

16. Cutolo M, Sulli A, Pizzorni C, Accardo S. Nailfold videocapillaroscopy assessment of microvascular damage in systemic sclerosis. J Rheumatol 2000; 27(1):155-60.

17. Hughes M, Hodgson R, Harris J, Porter N, Jackson S, Kirwadi A, et al. Imaging calcinosis in patients with systemic sclerosis by radiography, computerised tomography and magnetic resonance imaging. Semin Arthritis Rheum 2019; 49(2):279-82. doi: 10.1016/j.semarthrit.2019.03.001.

18. Bruni C, Guiducci S, Bellando-Randone S, Matucci-Cerinic M. Avascular bone necrosis: An underestimated complication of systemic sclerosis. Semin Arthritis Rheum 2017; 47(1):e3-e5. doi: 10.1016/j.semarthrit.2017.03.015.

19. Freire V, Bazeli R, Elhai M, Campagna R, Pessis E, Avouac J, et al. Hand and wrist involvement in systemic sclerosis: US features. Radiology 2013; 269(3):824-30. doi: 10.1148/radiol.13121994. 